\title{
Serological and structural characterization of the 0-antigens of the unclassified Proteus mirabilis strains TG 83, TG 319, and CCUG 10700 (OA)
}

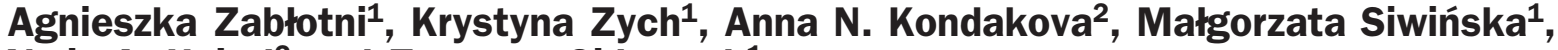 \\ Yuriy A. Knirel ${ }^{2}$ and Zygmunt Sidorczyk ${ }^{1}$ \\ 1 Department of General Microbiology, Institute of Microbiology and Immunology, University of Łódź, Łódź, Poland \\ 2 N.D. Zelinsky Institute of Organic Chemistry, Russian Academy of Sciences, Moscow, Russian Federation
}

Received: 2006.12.11, Accepted: 2007.05.10, Published online first: 2007.10.01

\begin{abstract}
Introduction: Lipopolysaccharide (endotoxin, LPS) is an important potential virulence factor of Proteus rods. The serological specificity of the bacteria is defined by the structure of the O-polysaccharide chain (O-antigen) of the LPS. Until now, 76 O-serogroups have been differentiated among Proteus strains.

Materials and Methods: LPSs were isolated from Proteus mirabilis TG 83, TG 319, and CCUG 10700 (OA) strains by phenol/water extraction. Antisera were raised by immunization of rabbits with heat-killed bacteria. Serological investigations were performed using enzyme immunosorbent assay, passive immunohemolysis, inhibition of both assays, absorption of antisera, and Western blot.

Results: The cross-reactive epitope shared by these strains and P. penneri O72a,O72b is located on the O-polysaccharide and is most likely associated with an $\alpha-\mathrm{D}-\mathrm{Gl} p-(1 \rightarrow 6)-\beta-\mathrm{D}-\mathrm{Gal} p \mathrm{NAc}$ disaccharide fragment. The serological data indicated the occurrence of two core types in the LPSs studied, one characteristic for P. mirabilis TG 319 and CCUG 10700 (OA) and the other for P. mirabilis TG 83 and O57.

Conclusions: The serological and structural data showed that P. mirabilis TG 83, TG 319, CCUG 10700 (OA), and O57 have the same O-antigen structure and could be qualified to the Proteus O57 serogroup.
\end{abstract}

Key words: Proteus, lipopolysaccharide, O-serogroup, serological classification.

Abbreviations: EIA - enzyme immunosorbent assay, LPS - lipopolysaccharide, PIH - passive immunohemolysis, CCUG Culture Collection of the University of Goeteborg.

Corresponding author: Prof. Zygmunt Sidorczyk, Ph.D., Department of General Microbiology, Institute of Microbiology and Immunology, University of Łódź, Banacha 12/16, 90-237 Łódź, Poland, tel.: +48 42 635-44-69, fax: +48 42 665-58-18, e-mail: zsidor@biol.uni.lodz.pl

\section{INTRODUCTION}

Gram-negative bacteria of the genus Proteus are widely distributed in the environment, such as soil, water, and sewage, and represent a part of the normal microflora of human and animal intestines. They are opportunistic pathogens which in favorable conditions cause intestine and urinary tract infections that may lead to serious complications, such as acute or chronic pyelonephritis, the formation of bladder and kidney stones, and catheter obstruction [15, 19]. In addition, Proteus strains may be a source of wound, burn, skin, nose, and throat infections [10]. P. mirabilis also plays an etiopathogenic role in rheumatoid arthritis [21]. The genus Proteus is currently divided into five species, including $P$. vulgaris, $P$. mirabilis, $P$. penneri, $P$. hauseri, and $P$. myxofaciens, as well as three unnamed Proteus genomospecies 4, 5, and 6 $[10,11]$.

Lipopolysaccharide (endotoxin, LPS) is an important potential virulence factor of Proteus [14]. The serological specificity of the bacteria is defined by the structure of the O-polysaccharide chain (O-antigen) of the LPS. Based on the O-antigens, strains of two species, $P$. vulgaris and $P$. mirabilis, were originally classified into 49 O-serogroups [2]. Our serological studies combined with structural elucidation of the O-polysaccharides resulted in reclassification of some of the existing 49 
O-serogroups and the creation of 18 new O-serogroups (O52, O56, O58-O73) for the third medically important species, $P$. penneri, as well as $P$. hauseri, $P$. myxofaciens, and Proteus genomospecies [1, 15, 24, 25]. Similar studies were also performed with $P$. mirabilis and $P$. vulgaris strains from the collections of Penner and Hennessy [12] and Larsson et al. [9]. As a result, about half of them $(\mathrm{O} 8, \mathrm{O} 23, \mathrm{O} 34, \mathrm{O} 40, \mathrm{O} 65, \mathrm{O} 69)$ were classified into the existing serogroups and a further six serogroups (O50, O53, O54, O55, O74, O75) were proposed for the others [3-6, 13, 22, 23].

Here we report the serological characterization of the LPSs of three unclassified $P$. mirabilis strains, TG 83, TG 319 [12], and CCUG 10700 (OA) [9], all of which are candidates for the Proteus serogroup O57.

\section{MATERIALS AND METHODS}

\section{Bacterial strains and growth}

Proteus mirabilis TG 83 and TG 319 were kindly provided by Prof. J. L. Penner (Department of Medical Genetics, University of Toronto, Canada). P. mirabilis OA strain CCUG 10700 as well as $P$. myxofaciens strain CCUG 18769 were obtained from the Culture Collection of the University of Goeteborg, Goeteborg, Sweden. Twenty-four strains of $P$. penneri came from the Collection of the Department of General Microbiology, University of Łódź, Poland. The P. hauseri strain was kindly provided by C. M. O'Hara and D. J. Brenner (Centers for Disease Control and Prevention, Atlanta, Georgia, USA). P. vulgaris (27) and P. mirabilis (39) strains were from the Czech National Collection of Type Cultures (CNCTC, National Institute of Public Health, Prague, Czech Republic). The bacteria were cultivated under aerobic conditions on nutrient broth (BTL, Łódź, Poland). Dry bacterial mass was obtained as described elsewhere [8].

\section{Isolation and degradation of the LPS}

LPSs were obtained from bacterial cells by hot phenol/water extraction [20] and purified using a cold aqueous $50 \% \mathrm{CCl}_{3} \mathrm{CO}_{2} \mathrm{H}$ precipitation procedure as described elsewhere [27].

\section{Rabbit antisera and serological assays}

Polyclonal $P$. mirabilis OA, TG 319, and TG 83 O-antisera were obtained by immunization of rabbits with heat-inactivated bacteria according to a published procedure [26]. Passive immunohemolysis test (PIH), enzyme immunosorbent assay (EIA), inhibition of these two tests, as well as absorption experiments were carried out as described elsewhere [17]. SDS/PAGE, electrotransfer of the LPS from gels to nitrocellulose sheets, and immunostaining were performed according to a published procedure [17].

\section{RESULTS AND DISCUSSION}

In order to reveal a possible serological relatedness of $P$. mirabilis TG 83, TG 319, and CCUG 10700 (OA) to each other and to other Proteus strains, O-antisera against these three strains were tested in PIH and EIA with the LPSs of 94 Proteus strains, including 40 $P$. mirabilis, 27 P. vulgaris, and $24 P$. penneri strains as well as one strain each of $P$. myxofaciens, $P$. hauseri and Proteus genomospecies 4. Only five LPSs were crossreactive, namely those of $P$. mirabilis TG 83, TG 319, CCUG 10700, O57 and, in addition, $P$. penneri 4 (O72a,72b). The data of the tests and the amount of each antigen necessary for the inhibition of the reactions in PIH and EIA are given in Table 1.

The strongest cross-reactivity with all $\mathrm{O}$-antisera was observed for the LPSs of $P$. mirabilis TG 83, TG 319, and CCUG 10700 and O57. It was on the same level as the reactivity of the homologous LPS, suggesting serological identity of all four strains. The LPS of $P$. penneri O72a,72b showed a weaker cross-reactivity and a weaker inhibiting activity when tested in the homologous systems with all the $\mathrm{O}$-antisera used.

In Western blot (Fig. 1), all O-antisera clearly recognized slow migrating bands of both homologous and heterologous LPS, and the banding patterns of $P$. mirabilis TG 83, TG 319, CCUG 10700, and O57 were almost identical. These bands correspond to high-molecular-mass LPS species with O-polysaccharides consisting of a large number of repeating units, and hence the cross-reactive epitope(s) is located on the O-polysaccharide. The recognition by heterologous $\mathrm{O}$-antisera of fast migrating bands of $P$. mirabilis TG 83 and O57 LPS, corresponding to the core-lipid A moiety, was different from that of TG 319 and CCUG 10700. No binding was observed for the low-molecular-mass LPS species of $P$. penneri O72a,72b.

For a more detailed epitope characterization, the antigens were tested in $\mathrm{PIH}$ with $\mathrm{O}$-antisera after absorption with various LPSs (Table 2). The reactivity of the O-antisera with all the tested antigens was completely abolished when they were absorbed with the homologous LPS. Absorption of O-antisera with LPS from either $P$. mirabilis TG 319 or CCUG 10700 removed all cross-reactive antibodies against the other LPS of the set. In contrast, absorption with $P$. mirabilis TG 83 and 057 LPS of $\mathrm{O}$-antisera against $P$. mirabilis TG 319 or CCUG 10700 left a small fraction of antibodies specific to the homologous LPS (titer 1:800/1600). This finding and the Western blot data (see above) allowed the suggestion that this fraction recognized an epitope(s) in the LPS core region, which seems to be different in TG 83, O57, and two other strains.

Absorption of all O-antisera with the LPS of $P$. penneri $\mathrm{O} 72 \mathrm{a}, 72 \mathrm{~b}$ decreased the level of antibodies from the titer $1: 25,600 / 51,200$ to $1: 12,800$, thus confirming the presence in all the LPSs studied of an epitope common to the $P$. penneri O72a,72b LPS. As revealed by the Western blot data (see above), this epitope is located in the O-polysaccharide region. 
Table 1. Reactivity of O-antisera against $P$. mirabilis TG 83, TG 319, and CCUG 10700 (OA) strains with the Proteus LPS ${ }^{\mathrm{a}, \mathrm{b}}$

\begin{tabular}{|c|c|c|c|c|}
\hline \multirow{2}{*}{ LPS from } & \multicolumn{2}{|c|}{ Reciprocal titer for the LPS } & \multicolumn{2}{|c|}{ Minimal inhibitory dose (ng) of the LPS } \\
\hline & $\mathrm{PIH}$ & EIA & PIH & EIA \\
\hline \multicolumn{5}{|c|}{ P. mirabilis TG $83 \mathrm{O}$-antiserum } \\
\hline P. mirabilis TG 83 & 51200 & 512000 & 2 & 2 \\
\hline P. mirabilis TG 319 & 51200 & 512000 & 2 & 2 \\
\hline P. mirabilis CCUG 10700 & 51200 & 512000 & 2 & 2 \\
\hline P. mirabilis $\mathrm{O} 57$ & 51200 & 512000 & 2 & 2 \\
\hline P. penneri $\mathrm{O} 72 \mathrm{a}, 72 \mathrm{~b}$ & 6400 & 64000 & 250 & 500 \\
\hline \multicolumn{5}{|c|}{ P. mirabilis TG 319 O-antiserum } \\
\hline P. mirabilis TG 83 & 25600 & 256000 & 2 & 2 \\
\hline P. mirabilis TG 319 & 25600 & 256000 & 2 & 2 \\
\hline P. mirabilis CCUG 10700 & 25600 & 256000 & 2 & 2 \\
\hline P. mirabilis $\mathrm{O} 57$ & 25600 & 256000 & 2 & 2 \\
\hline P. penneri $\mathrm{O} 72 \mathrm{a}, 72 \mathrm{~b}$ & 3200 & 32000 & 500 & 1000 \\
\hline \multicolumn{5}{|c|}{ P. mirabilis CCUG 10700 (OA) O-antiserum } \\
\hline P. mirabilis TG 83 & 51200 & 512000 & 2 & 2 \\
\hline P. mirabilis TG 319 & 51200 & 512000 & 2 & 2 \\
\hline P. mirabilis CCUG 10700 & 51200 & 512000 & 2 & 4 \\
\hline P. mirabilis $\mathrm{O} 57$ & 51200 & 512000 & 2 & 2 \\
\hline P. penneri $\mathrm{O} 72 \mathrm{a}, 72 \mathrm{~b}$ & 3200 & 8000 & 500 & 500 \\
\hline
\end{tabular}

${ }^{a}$ LPS and alkali-treated LPS were used as antigen in EIA and PIH, respectively.

${ }^{\mathrm{b}}$ Data for homologous LPS are italicized.

The serological results were in agreement with the structural analysis of the O-polysaccharides isolated from the LPS of $P$. mirabilis TG 83 and TG 319. Comparison of their ${ }^{13} \mathrm{C}-\mathrm{NMR}$ spectra with each other and with that of $P$. mirabilis ATCC 49995 (serogroup O57) studied earlier [18] using the "finger-print" method showed that they are essentially identical, and hence the three O-polysaccharides have the same struc- ture shown in Fig. 2 (for the assignment of the ${ }^{1} \mathrm{H}$ - and ${ }^{13} \mathrm{C}-\mathrm{NMR}$ spectra, see published data [18]). Based on the combined serological and structural data, we consider P. mirabilis TG 83, TG 319, and CCUG 10700 (OA) as candidates for the Proteus O57 serogroup as the next three representatives.

A comparison of the O-polysaccharide structures (Fig. 2) allowed the suggestion that the cross-reactive
A

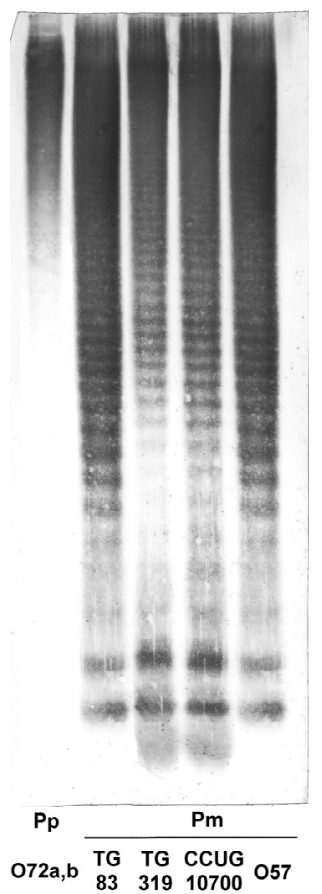

B

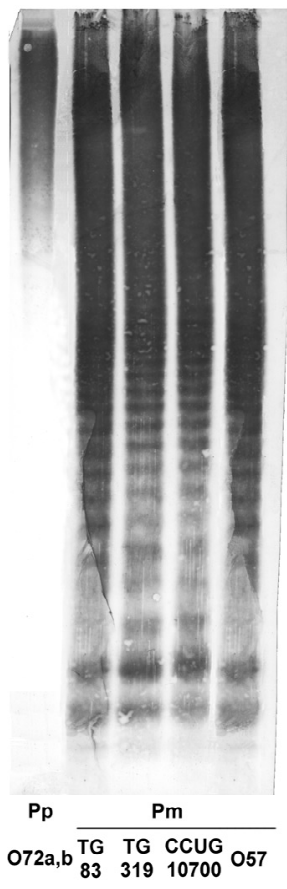

C

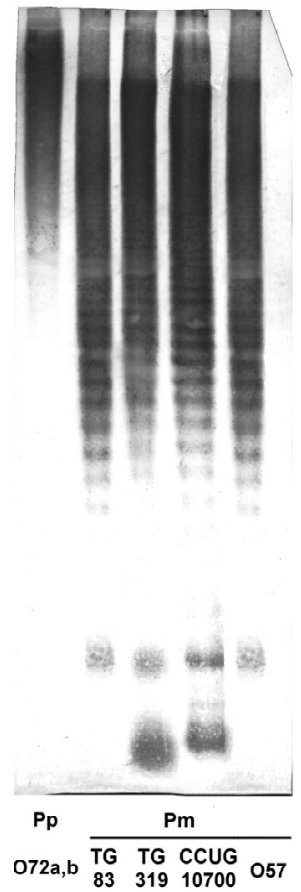

Fig. 1. Western blot of Proteus LPS with O-antisera against $P$. mirabilis TG 83 (A), TG 319 (B) and CCUG 10700 (C). Pm and Pp stand for $P$. mirabilis and $P$. penneri, respectively. 
Table 2. Passive immunohemolysis data of alkali-treated LPS with absorbed O-antisera against P. mirabilis TG 83, TG 319, and CCUG 10700 (OA) strains ${ }^{\mathrm{a}, \mathrm{b}}$

\begin{tabular}{|c|c|c|c|c|c|}
\hline \multirow{3}{*}{$\begin{array}{l}\text { O-antisera absorbed } \\
\text { with the alkali-treated LPS from }\end{array}$} & \multicolumn{5}{|c|}{$\begin{array}{c}\text { Reciprocal titer of absorbed } \\
\text { O-antisera with the alkali-treated LPS from }\end{array}$} \\
\hline & \multicolumn{4}{|c|}{ P. mirabilis } & \multirow{2}{*}{$\begin{array}{l}\text { P. penneri } \\
\text { O72a,72b }\end{array}$} \\
\hline & TG 83 & TG 319 & CCUG 10700 & O57 & \\
\hline \multicolumn{6}{|l|}{ P. mirabilis TG $83 \mathrm{O}$-antiserum } \\
\hline Control & 51200 & 51200 & 51200 & 51200 & 6400 \\
\hline P. mirabilis TG 83 & $<100$ & $<100$ & $<100$ & $<100$ & $<100$ \\
\hline P. mirabilis TG 319 & 800 & $<100$ & $<100$ & 800 & $<100$ \\
\hline P. mirabilis CCUG 10700 & 800 & $<100$ & $<100$ & 800 & $<100$ \\
\hline P. mirabilis $\mathrm{O} 57$ & $<100$ & $<100$ & $<100$ & $<100$ & $<100$ \\
\hline P. penneri $\mathrm{O} 72 \mathrm{a}, 72 \mathrm{~b}$ & 12800 & 12800 & 12800 & 12800 & $<100$ \\
\hline \multicolumn{6}{|l|}{ P. mirabilis TG 319 O-antiserum } \\
\hline Control & 25600 & 25600 & 25600 & 25600 & 3200 \\
\hline P. mirabilis TG 83 & $<100$ & 800 & 800 & $<100$ & $<100$ \\
\hline P. mirabilis TG 319 & $<100$ & $<100$ & $<100$ & $<100$ & $<100$ \\
\hline P. mirabilis CCUG 10700 & $<100$ & $<100$ & $<100$ & $<100$ & $<100$ \\
\hline P. mirabilis $\mathrm{O} 57$ & $<100$ & $<100$ & $<100$ & $<100$ & $<100$ \\
\hline P. penneri $\mathrm{O} 72 \mathrm{a}, 72 \mathrm{~b}$ & 12800 & 12800 & 12800 & 12800 & $<100$ \\
\hline \multicolumn{6}{|c|}{ P. mirabilis CCUG 10700 O-antiserum } \\
\hline Control & 51200 & 51200 & 51200 & 51200 & 3200 \\
\hline P. mirabilis TG 83 & $<100$ & 1600 & 1600 & $<100$ & $<100$ \\
\hline P. mirabilis TG 319 & $<100$ & $<100$ & $<100$ & $<100$ & $<100$ \\
\hline P. mirabilis CCUG 10700 & $<100$ & $<100$ & $<100$ & $<100$ & $<100$ \\
\hline P. mirabilis $\mathrm{O} 57$ & $<100$ & $<100$ & $<100$ & $<100$ & $<100$ \\
\hline P. penneri $\mathrm{O} 72 \mathrm{a}, 72 \mathrm{~b}$ & 12800 & 12800 & 12800 & 12800 & $<100$ \\
\hline
\end{tabular}

a Sheep red blood cells were used as a control.

b Data for homologous LPS are italicized.

epitope of $P$. penneri $\mathrm{O} 72 \mathrm{a}, 72 \mathrm{~b}[7,16]$ is associated with an $\alpha$-D-Glc $p$ - $(1 \rightarrow 6)-\beta$-D-GalpNAc disaccharide fragment shared by all the strains studied.

In conclusion, 1) the serological and structural data showed that $P$. mirabilis TG 83, TG 319, CCUG 10700 (OA), and $\mathrm{O} 57$ have the same O-antigen structure and may be considered candidates for the Proteus O57 serogroup; 2 ) the cross-reactive epitope shared by these strains and $P$. penneri $\mathrm{O} 72 \mathrm{a}, 72 \mathrm{~b}$ is located on the $\mathrm{O}$-polysaccharide and is most likely associated with an $\alpha$-D-Glc $p$ - $(1 \rightarrow 6)-\beta$-D-Gal $p$ NAc disaccharide fragment; 3 ) the serological data pointed to the occurrence of two

Proteus mirabilis O57 [18, this work]

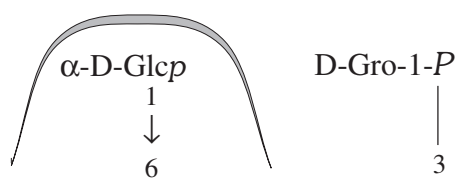

$\rightarrow 6)-\beta$-D-Galp-( $1 \rightarrow 3)-\beta$-D-GalpNAc-( $1 \rightarrow 4)-\beta$-D-GalpNAc-( $1 \rightarrow 3)-\alpha-D-G a l p-(1 \rightarrow$

Proteus penneri O72a, 72b (P. penneri 1,4$)[16,24]$

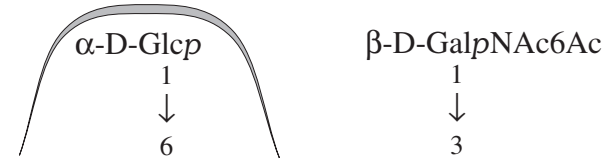

$\rightarrow 3$ )- $\beta$-D-GalpNAc-( $1 \rightarrow 4)-\alpha$-D-Galp-( $1 \rightarrow 6)$ - $\beta$-D-Glcp-( $1 \rightarrow$
Fig. 2. Chemical structures of the O-specific polysaccharides of the investigated $P$. mirabilis and $P$. penneri O72a,72b LPS with signed epitope responsible for cross-reactions. 
core types in the LPSs studied, one characteristic for P. mirabilis TG 319 and CCUG 10700 (OA) and the other for P. mirabilis TG 83 and O57.

Acknowledgment: This work was supported by the State Committee for Scientific Research (KBN, Poland, grant No. 2 PO5A 086 26) and the Council on Grants of the President of the Russian Federation for the Support of Young Russian Scientists (project No. MK-2204.2006.4). The authors thank Janusz Włodarczyk for excellent technical assistance in the preparation of the manuscript.

\section{REFERENCES}

1. Drzewiecka D., Zych K. and Sidorczyk Z. (2004): Characterization and serological classification of a collection of Proteus penneri clinical strains. Arch. Immunol. Ther. Exp., 52, 121-128.

2. Kauffman F. (1966): The bacteriology of Enterobacteriaceae. Wiliams and Wilkins Co., Baltimore, pp. 333-360.

3. Kołodziejska K., Kondakova A. N., Zych K., Senchenkova S. N., Shashkov A. S., Knirel Y. A. and Sidorczyk Z. (2003): Structure of the O-polysaccharide of a serologically separate strain of Proteus mirabilis TG 332, from a new proposed Proteus serogroup O50. Carbohydr. Res., 338, 2105-2109.

4. Kołodziejska K., Perepelov A. V., Zabłotni A., Drzewiecka D., Senchenkova S. N., Zych K., Shashkov A. S., Knirel Y. A. and Sidorczyk Z. (2006): Structure of the glycerol phosphate-containing O-polysaccharides and serological studies of the lipopolysaccharides of Proteus mirabilis CCUG 10704 (OE) and Proteus vulgaris TG 103 classified into a new Proteus serogroup, O54. FEMS Immunol. Med. Microbiol., 47, 267-274.

5. Kołodziejska K., Siwińska M., Zych K., Różalski A. and Sidorczyk Z. (2006): Characterization and serological classification of O-specific polysaccharide of Proteus mirabilis TG 276-90 from Proteus serogroup O34. Arch. Immunol. Ther. Exp., 54, 223-226.

6. Kondakova A. N., Kołodziejska K., Zych K., Senchenkova S. N., Shashkov A. S., Knirel Y. A. and Sidorczyk Z. (2003): Structure of the N-acetyl-L-rhamnosamine-containing O-polysaccharide of Proteus vulgaris TG 155 from a new Proteus serogroup O55. Carbohydr. Res., 338, 1999-2004.

7. Kondakova A. N., Toukach F. V., Senchenkova S. N., Arbatsky N. P., Shashkov A. S., Knirel Y. A., Zych K., Torzewska A., Kołodziejska K., Różalski A. and Sidorczyk Z. (2002): New structures of the O-specific polysaccharides of Proteus. Part 2. Polysaccharides containing O-acetylated groups. Biochemistry, 67, 201-211.

8. Kotełko K., Gromska W., Papierz M., Sidorczyk Z., Krajewska D. and Szer K. (1977): Core region of Proteus mirabilis lipopolysaccharide. J. Hyg. Epidemiol. Microbiol. Immunol., 21, 271-284.

9. Larsson P., Anderson H. E. and Norlen B. (1978): Serotyping in epidemiological tracing of nosocomially acquired Proteus mirabilis in a geriatric ward. Infection, 6, 105-110.

10. O’Hara C. M., Brenner F. W. and Miller J. M. (2000): Classification, identification and clinical significance of Proteus, Providencia and Morganella. Clin. Microbiol. Rev., 13, 534-546.
11. O’Hara C. M., Brenner F. W., Steigerwalt A. G., Hill B. C., Holmes B., Grimont P. A., Hawkey P. M., Penner J. L., Miller J. M. and Brenner D. (2000): Classification of Proteus vulgaris biogroup 3 with recognition of Proteus hauseri sp. nov., nom. rev. and unnamed Proteus genomospecies 4, 5 and 6. Int. J. Syst. Evol. Microbiol., 50, 1869-1875.

12. Penner J. L. and Hennessy J. N. (1980): Separate O-grouping schemes for serotyping clinical isolates of Proteus vulgaris and Proteus mirabilis. J. Clin. Microbiol., 12, 304-309.

13. Perepelov A. V., Zabłotni A., Shashkov A. S., Knirel Y. A. and Sidorczyk Z. (2006): Structure of the O-polysaccharide of Proteus mirabilis CCUG 10705 (OF) containing an amide of D-galacturonic acid with L-alanine. Carbohydr. Res., 341, 1969-1974.

14. Różalski A., Sidorczyk Z. and Kotełko K. (1997): Potential virulence factors of Proteus bacilli. Microbiol. Mol. Biol. Rev., 61, 65-89.

15. Sidorczyk Z., Kondakova A. N., Zych K., Senchenkova S. N., Shashkov A. S., Drzewiecka D. and Knirel Y. A. (2003): Structure of the O-polysaccharide from Proteus myxofaciens. Classification of the bacterium into a new Proteus O-serogroup. Eur. J. Biochem., 270, 3182-3188.

16. Sidorczyk Z., Toukach F. V., Zych K., Drzewiecka D., Arbatsky N. P., Shashkov A. S. and Knirel Y. A. (2002): Structural and serological relatedness of the O-antigens of Proteus penneri 1 and 4 from a novel Proteus serogroup O72. Eur. J. Biochem., 269, 358-363.

17. Sidorczyk Z., Zych K., Toukach F. V., Arbatsky N. P., Zabłotni A., Shashkov A. S. and Knirel Y. A. (2002): Structure of the O-polysaccharide and classification of Proteus mirabilis strain G1 in Proteus serogroup O3. Eur. J. Biochem., 269, 1406-1412.

18. Uhrin D., Brisson J.-R., MacLean L. L., Richards J. C. and Perry M. B. (1994): Application of 1D and 2D NMR techniques to the structure elucidation of the O-polysaccharide from Proteus mirabilis O:57. J. Biomol. NMR, 4, 615-630.

19. Warren J. W. (1996): Clinical presentations and epidemiology of urinary tract infection. In Mobley H. T. L. and Warren J. W. (eds.): Urinary Tract Infections. Molecular Pathogenesis and Clinical Management. ASM Press, Washington, DC, pp. 2-28.

20. Westphal O. and Jann K. (1965): Bacterial lipopolysaccharides. Extraction with phenol-water and further application of the procedure. Methods Carbohydr. Chem., 5, 83-91.

21. Wilson C., Thakore A., Isenberg D. and Ebringer A. (1997): Correlation between anti-Proteus antibodies and isolation rates of $P$. mirabilis in rheumatoid arthritis. Rheumatol. Int., 16, 187-189.

22. Zabłotni A., Perepelov A. V., Knirel Y. A. and Sidorczyk Z. (2005): Structure of the O-polysaccharide of Proteus mirabilis OC (CCUG 10702) from a new proposed Proteus serogroup O75. Carbohydr. Res., 340, 1908-1913.

23. Zabłotni A., Perepelov A. V., Kołodziejska K., Zych K., Knirel Y. A. and Sidorczyk Z. (2006): Classification of $P$. mirabilis TG 115 and CCUG 10701 into Proteus O23 serogroup based on chemical and serological studies of O-polysaccharides. Arch. Immunol. Ther. Exp., 54, 411-417.

24. Zych K., Kowalczyk M., Knirel Y. A. and Sidorczyk Z. (2000): New serogroups of the genus Proteus consisting of Proteus penneri strains only. Determination of some LPS epitopes responsible for their specificity. Adv. Exp. Med. Biol., 485, 339-344. 
25. Zych K., Perepelov A. V., Siwińska M., Knirel Y. A. and Sidorczyk Z. (2005) Structures of the O-polysaccharides and classification of Proteus genomospecies 4, 5 and 6 into respective Proteus serogroups. FEBS J., 272, 5536-5543.

26. Zych K., Świerzko A. and Sidorczyk Z. (1992): Serological characterization of Proteus penneri species novum. Arch. Immunol. Ther. Exp., 40, 89-92.
27. Zych K., Toukach F. V., Arbatsky N. P., Kołodziejska K., Senchenkova S. N., Shashkov A. S., Knirel Y. A. and Sidorczyk Z. (2001): Structure of the O-specific polysaccharide of Proteus mirabilis D52 and typing of this strain to Proteus serogroup O33. Eur. J. Biochem., 268, 4346-4351. 